\title{
Retrospective epidemiological study of urolithiasis in western Algeria over a period of 50 years
}

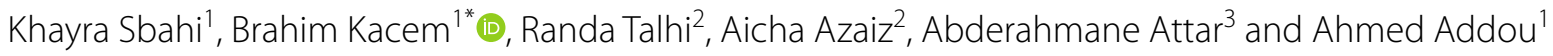

\begin{abstract}
Background: Urolithiasis is a pathology that changes with time and with the evolution of human societies. The prevalence of this pathology has gradually increased during the last decades, especially because of dietary changes.

Methods: This work is a retrospective descriptive epidemiological study of the temporal type carried out at the level of the urology service of the University Hospital Center of Oran between the first January 1965 and December 31, 2014. The objectives of this work are to study the epidemiological profile of urolithiasis and to determine the evolutionary trend of the disease over time.

Results: This study confirms some current data in the direction of an increase in surgical activity concerning the treatment of urinary stones. The analysis over time shows us a significant decrease $(p<0.01)$ in the male predominance between 1965 and 2014 with a M/F ratio which decreased from 3.09 to 1.82, as well as an increase in the average age, rising from 28.8 years in the period 1965-1974 to 48.3 years between 2005 and 2014.

Conclusion: The analysis of epidemiological data is essential to better evaluate the evolution of the urolithiasis disease, which was affirmed in our study, where a constant evolution of the characteristics of the disease was revealed, testifying the change of the socio-economic level in Algeria.
\end{abstract}

Keywords: Urolithiasis, Stones, Surgical treatment, Epidemiology

\section{Background}

Reflecting the sanitary conditions, eating habits and standard of living of the populations, the urolithiasis is constantly evolving both from the point of view of its epidemiological characteristics and its etiological factors. However, if one considers that the populations of the different countries of the world evolve globally toward an improvement of their living conditions and the level of medicalization, one can consider that the modifications of the urolithiasis disease are comparable in all the

*Correspondence: kacem1b62@gmail.com

${ }^{1}$ STEVA « Environmental Science and Technology and Valorisation

Laboratory», Départment of Biology, Faculty of Natural Sciences and Life,

University Abdelhamid Ibn Badis, 27000 Mostaganem, Algeria

Full list of author information is available at the end of the article countries of the world, with a rhythm specific to each country or each population group considered [1].

European, American and Asian epidemiological studies show that the prevalence of urolithiasis has gradually increased over the past 50 years, mainly due to dietary changes that are more geared toward salty and meat-eating diets [2].

Since all of the work done in Algeria has focused on urolithiasis in limited periods, we propose this study which covers a period of five decades. The objectives of this work are to study the epidemiological profile of urolithiasis and to determine the evolutionary trend of the disease over time. 


\section{Methods}

This is a retrospective descriptive epidemiological study of the temporal type performed at the level of the Urology service of the University Hospital Center between January 1, 1965, and December 31, 2014.

This work concerns patients operated on for urolithiasis. Included in this study are subjects of both sexes, of all age groups with a first or recurrent lithiasis episode, regardless of the anatomical location of the urinary calculus. This study excludes patients who have undergone diagnostic procedures only (without operative interventions) as well as those whose stone was extracted using extracorporeal lithotripsy (ECL), a technique that only started in 2006, due to unavailability of data.

The data collection was exhaustive, including all patients operated for urolithiasis during the period between the first of January, 1965 and December 31st, 2014. The operating room registers were used to determine the number of surgical procedures performed for each year, as well as other patient information.

Data analysis involves a comparative temporal analysis of the number of interventions based on several variables. An ANOVA test was used to compare the averages. For the comparison of percentages and the study of the evolutionary trend over time, the trend chi-square test was used. In the case of a single sample, the t-test was used. For these tests, the significance level was set at $p<0.05$.

The data were entered and analyzed on SPSS software version 17 . The trend chi-square values were calculated manually on the Excel software.

\section{Results}

This work involved 3989 urolithiasis with a male/female $(\mathrm{M} / \mathrm{F})$ ratio of 2.07 . The average age was $40.96 \pm 19.33$ with a minimum of 1 year and a maximum of 105 years.

\subsection{General temporal analysis}

A considerable evolutionary trend in the number of interventions was recorded during the period between 1965 and 2014. A peak of 143 interventions was noted during the year 1985, this number decreases to 133 in 1986 and 128 in 1987 until reaching 23 in 1995. From 1996, this number has resumed an increase with values varying between 88 and 143, the latter value represents a second peak that was recorded in 2008 (Fig. 1).

By dividing our study period by decade, we obtain five periods of ten years each. The highest numbers were

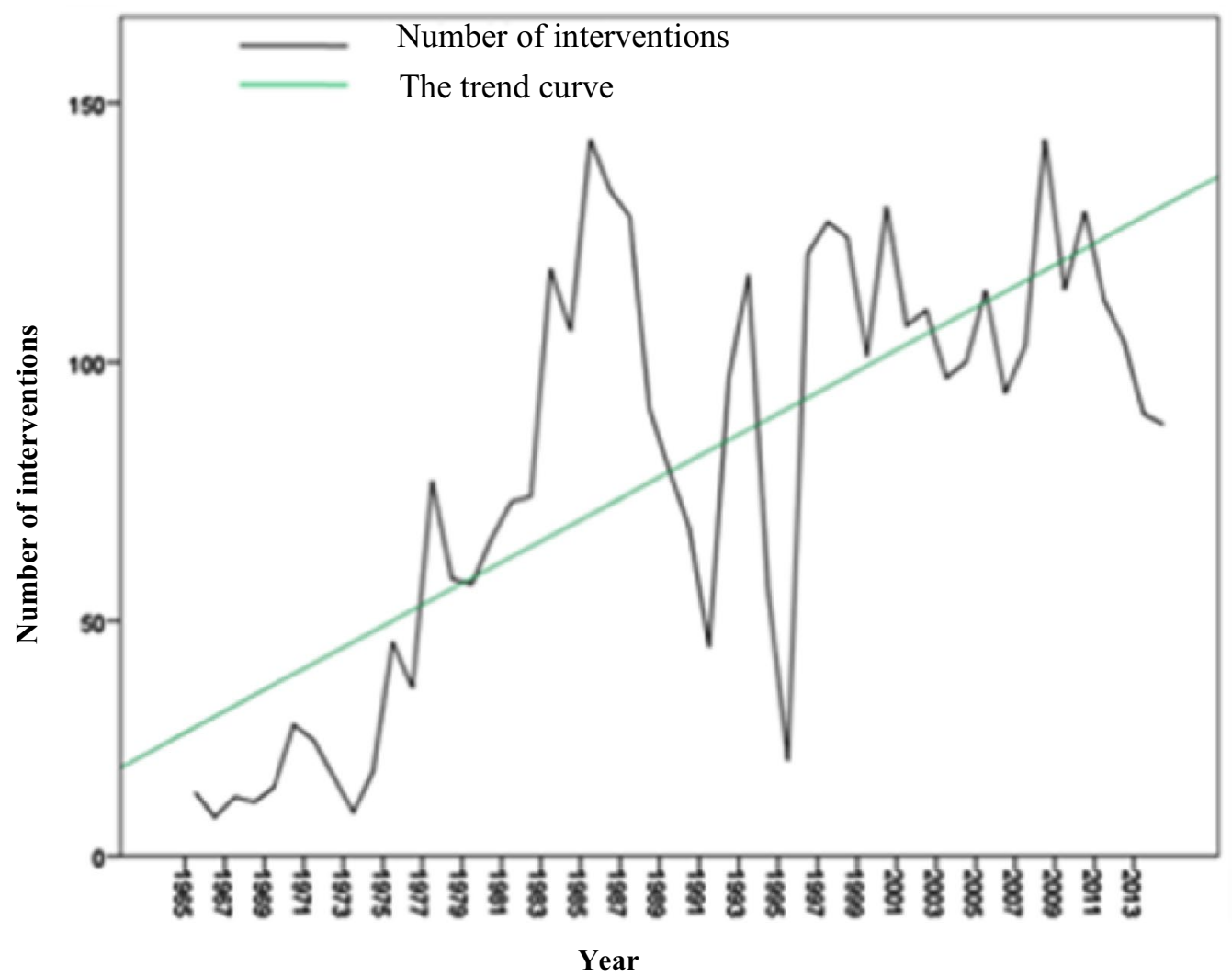

Fig. 1 Annual evolution of the number of operative interventions for urolithiasis between 1965 and 2014 


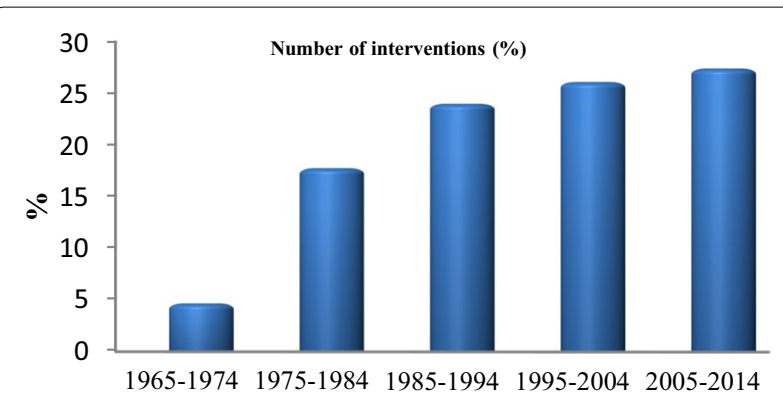

Fig. 2 Evolution of the number of operative interventions for urolithiasis between 1965 and 2014 by decade

recorded in the fifth and fourth periods with 1091 and 1040 interventions, respectively, while between 1965 and 1974, only 189 interventions were realized indicating a significant increase in the number of lithiasis in this University Hospital Center during the last five decades (one-way ANOVA test: $\mathrm{F}=22.354, p=0.000<0.05$ and $\mathrm{t}$-test between the first and the last period: $\mathrm{t}=15.603$, $p=0.000<0.05)$ (Fig. 2).

\subsection{According to sex}

The distribution of lithiasic patients by sex reveals a male predominance which has significantly changed over the past five decades $(P<0.01)$ (Table 1$)$. During the first period (1965-1974), male subjects accounted for $75.5 \%$ of lithiasis compared with $24.5 \%$ for females, which corresponds to a M/F ratio of 3.09, a value which decreased over time until reaching its minimum value between the years 2005 and 2014 with 1.82 .

\subsection{According to the age}

According to our study, there was a highly significant increase in the age of lithiasis $(P<10-6)$ (Table 2$)$, which had an average age of 28.8 years during the period from 1965 to 1974 , average that has increased steadily to 48.3 years over the 2005-2014 period, which represents the highest value compared to other periods in our study.

By classifying our subjects by age group, there is a radical change in the distribution of lithiasis over time, manifested by a shift in frequency peaks toward the higher age groups (Fig. 3).

For the first period, children aged of 10 years and under are the most exposed to the risk of urolithiasis with a percentage of $26.1 \%$. For the second and the third periods, subjects aged between 21 and 30 years are the most affected by lithiasis with rates of $27.1 \%$ and $21 \%$, respectively. We note that during the first three periods, the last age class (>70) was the least affected by urolithiasis.

Table 1 Sex distribution of urolithiasis patients between 1965 and 2014 by decade

\begin{tabular}{|c|c|c|c|c|c|c|}
\hline \multirow[t]{3}{*}{ Periods } & \multicolumn{5}{|l|}{ Sex } & \multirow[t]{3}{*}{$\mathbf{P}$} \\
\hline & \multicolumn{2}{|l|}{ Male } & \multicolumn{2}{|l|}{ Female } & \multirow[t]{2}{*}{ Sex-ratio (H/F) } & \\
\hline & Number & $\%$ & Number & $\%$ & & \\
\hline $\begin{array}{l}1965-1974 \\
N=189(4.7 \%)\end{array}$ & 142 & 75.5 & 46 & 24.5 & 3.09 & $\begin{array}{l}<0.01 \text { chi-square calcu- } \\
\text { lated value }=14,4927 \\
(\mathrm{DF}=4)\end{array}$ \\
\hline $\begin{array}{l}1975-1984 \\
N=712(17.8 \%)\end{array}$ & 504 & 72.1 & 195 & 27.9 & 2.58 & \\
\hline $\begin{array}{l}1985-1994 \\
N=957(24 \%)\end{array}$ & 619 & 66.4 & 313 & 33.6 & 1.98 & \\
\hline $\begin{array}{l}1995-2004 \\
N=1040(26.1 \%)\end{array}$ & 691 & 66.6 & 347 & 33.4 & 1.99 & \\
\hline $2005-2014 \mathrm{~N}=1091(27.4 \%)$ & 696 & 64.5 & 383 & 35.5 & 1.82 & \\
\hline
\end{tabular}

Table 2 Evolution of the average age of lithiasis in the Urology service of the University Hospital Center of Oran during the last five decades

\begin{tabular}{llllll}
\hline Variables & Periods & & & \multicolumn{1}{c}{$\boldsymbol{P}$} \\
\cline { 2 - 6 } & $\mathbf{1 9 6 5 - 1 9 7 4}$ & $\mathbf{1 9 7 5 - 1 9 8 4}$ & $\mathbf{1 9 8 5 - 1 9 9 4}$ & $\mathbf{1 9 9 5 - 2 0 0 4}$ & $\mathbf{2 0 0 5 - 2 0 1 4}$ \\
& Avg \pm SD & Avg \pm SD & Avg \pm SD & Avg \pm SD & Avg \pm SD \\
\hline Average age & $28.8 \pm 21$ & $34.1 \pm 19.8$ & $37.3 \pm 19.9$ & $42.6 \pm 17.5$ & $48.3 \pm 16.8$
\end{tabular}

Avg: average, SD: standard deviation 
As for the period between 1995 and 2004, subjects aged from 31 to 40 years represented the highest percentage (21.6\%). This gap of distribution continues during the last period (2005-2014), where the highest peak was recorded to the subjects aged from 51 to 60 years with $21.3 \%$. It is reported that in the last two periods, the children of ten and less years old represented the lowest percentages.

\subsection{According to the stone location}

A change in the distribution of stones over time has been observed. As regard to the lateralization according to periods, no significant difference was recorded (Table 3). It is noted that during the first four periods, the urolithiasis of the right side was predominant, while the reverse was observed for the period between 2005 and 2014 with a percentage of $50.4 \%$ for the left side.

A significant evolution in the localization in the upper or the lower urinary tract was noted (Table 4). Between 1965 and 1974, the stones were localized of advantage

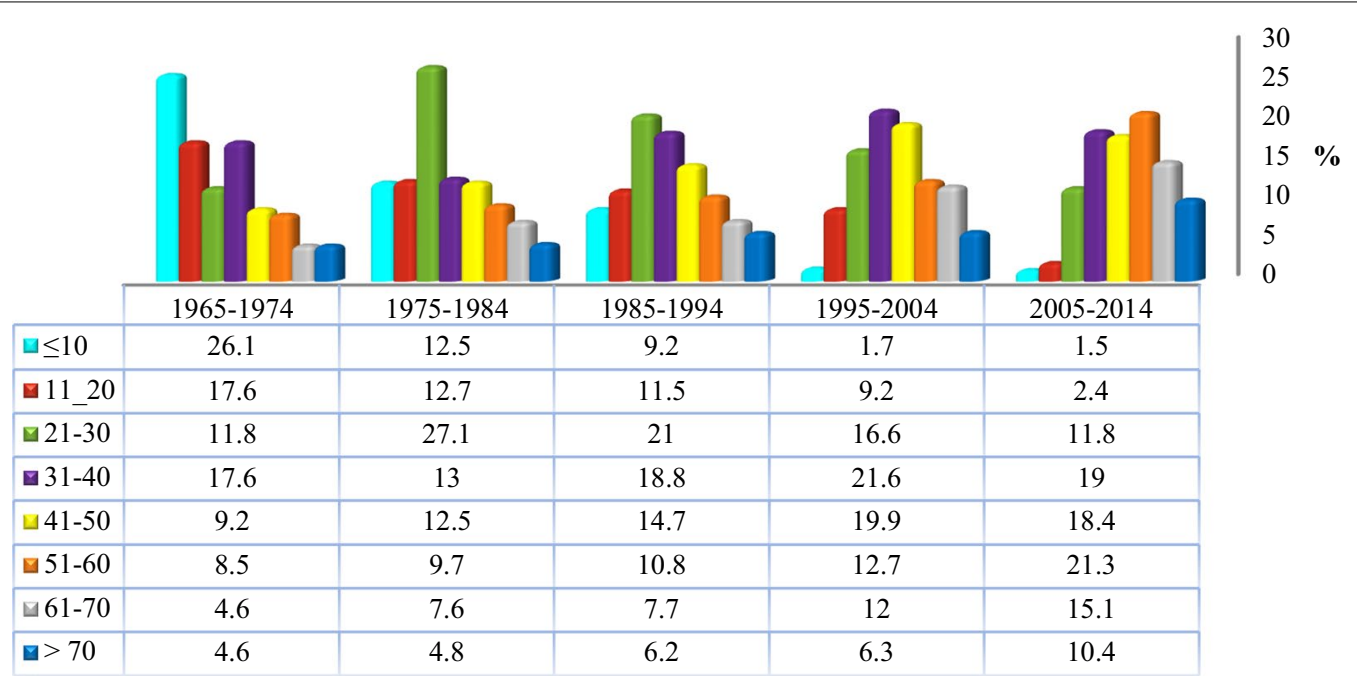

Fig. 3 Distribution of lithiasis of Urology service of the University Hospital center of Oran according to the periods by age group

Table 3 Comparison of the laterality of lithiasis between 1965 and 2014 by decade

\begin{tabular}{|c|c|c|c|c|c|c|c|c|c|c|c|}
\hline \multirow[t]{3}{*}{ Laterality } & \multicolumn{10}{|l|}{ Periods } & \multirow[t]{3}{*}{$\mathbf{P}$} \\
\hline & \multicolumn{2}{|c|}{ 1965-1974 } & \multicolumn{2}{|c|}{ 1975-1984 } & \multicolumn{2}{|c|}{ 1985-1994 } & \multicolumn{2}{|c|}{ 1995-2004 } & \multicolumn{2}{|c|}{$2005-2014$} & \\
\hline & Number & $\%$ & Number & $\%$ & Number & $\%$ & Number & $\%$ & Number & $\%$ & \\
\hline Left side & 22 & 41.5 & 201 & 48.6 & 298 & 46.1 & 339 & 48.2 & 404 & 50.4 & NS (chi-square calculated \\
\hline Right side & 31 & 58.5 & 213 & 51.4 & 349 & 53.9 & 364 & 51.8 & 398 & 49.6 & value $=1.8877 \mathrm{DF}=4)$ \\
\hline
\end{tabular}

Table 4 Comparison of the general localization of lithiasis between 1965 and 2014 by decade

\begin{tabular}{|c|c|c|c|c|c|c|c|c|c|c|c|}
\hline \multirow[t]{3}{*}{ Localization } & \multicolumn{10}{|l|}{ Periods } & \multirow[t]{3}{*}{$\mathbf{P}$} \\
\hline & \multicolumn{2}{|c|}{ 1965-1974 } & \multicolumn{2}{|c|}{ 1975-1984 } & \multicolumn{2}{|c|}{ 1985-1994 } & \multicolumn{2}{|c|}{ 1995-2004 } & \multicolumn{2}{|c|}{ 2005-2014 } & \\
\hline & Number & $\%$ & Number & $\%$ & Number & $\%$ & Number & $\%$ & Number & $\%$ & \\
\hline Upper urinary tract & 91 & 48.1 & 467 & 65.6 & 693 & 72.5 & 738 & 71 & 827 & 75.8 & $\begin{array}{l}<0.001 \\
\text { (chi-square } \\
\text { calculated }\end{array}$ \\
\hline Low urinary tract & 98 & 51.9 & 245 & 34.4 & 263 & 27.5 & 302 & 29 & 264 & 24.2 & $\begin{array}{l}\text { value }=47.44 \\
D F=4)\end{array}$ \\
\hline
\end{tabular}


in the lower urinary tract (51.9\%). This situation was reversed from the second period when the lithiasis were mainly situated in the upper side.

By studying the results of the general localization of lithiasis by sex, we observe that this modification of the seat of stones over time in the upper or lower urinary tract concerns in reality only the male sex. On the other hand, for the female sex, the upper urinary tract was still the preferential location during all periods, but with frequencies which evolved from $69.6 \%$ for the first period (1965-1974) to $94.5 \%$ for the last period between 2005 and 2014 (Table 5).

\subsection{According to the size and the number}

It is found that a significant majority of lithiasis formed a single stone for the five decades studied $(P<0.001)$ (Table 6). The highest percentage $(89.4 \%)$ was observed during the period between 1965 and 1974, a value that tends to decrease significantly over time $(P<0.001)$, in favor of multiple lithiasis which represents approximately a third of stones after 1994.

As for the average size of the stones, it is found that it was $2.41 \mathrm{~cm}$ during the first period. This size decreases significantly $(P<0.002)$. An average of $2.35 \mathrm{~cm}$ was recorded during the period of 1975-1984 against $2.26 \mathrm{~cm}$ for the period of 1985-1994, $2.32 \mathrm{~cm}$ for that from 1995 to 2004 and $2.05 \mathrm{~cm}$ for the period 2005-2014.

\section{Discussion}

This study confirms some current data for increased surgical procedures for the treatment of urinary stones [3-5]. According to our data, this trend of growth can be clearly observed in the increase of the annual number of interventions, with a rapid rise that reached its maximum of 143 interventions in 1985. The number varied afterward, and hovered around 100 interventions a year, with the exceptions of 45, 56 and 23 interventions registered in the years 1991, 1994 and 1995, respectively. This fall is due to a lack of data (missing pages from the operating block registers).

On the overall, the growth in the number of procedures for urolithiasis in our hospital was $577 \%$ between 1965 and 2014. The greatest increase was recorded over the two periods: 1965-1974 and 1975-1984 (377\%) with an increase from 189 to 712 interventions over a 10 year period. This can be explained by the development of the population of the city of Oran and Algeria in general in this post-independence period, the improvement of the living conditions, and even the improvement of the structure of the Urology service. The decrease observed in the years 2006 and after 2010 can be explained by the acquisition of a lithotriptor by the UHC of Oran in 2006 and by the appearance of a new University Hospital Institution in the city of Oran in 2004 but which became operational only in 2010. This establishment, in addition to private clinics, treats lithiasis patients in the region, which means

Table 5 Comparison of the general anatomical location of urolithiasis between 1965 and 2014 by decade, according to the sex

\begin{tabular}{|c|c|c|c|c|c|c|c|c|c|c|}
\hline \multirow[t]{4}{*}{ Gender } & \multicolumn{10}{|c|}{ Periods } \\
\hline & \multirow{2}{*}{\multicolumn{2}{|c|}{$\frac{1965-1974}{\text { Localization }}$}} & \multicolumn{2}{|c|}{ 1975-1984 } & \multicolumn{2}{|c|}{ 1985-1994 } & \multicolumn{2}{|c|}{ 1995-2004 } & \multicolumn{2}{|c|}{$2005-2014$} \\
\hline & & & & & & & & & & \\
\hline & UUT & LUT & UUT & LUT & UUT & LUT & UUT & LUT & UUT & LUT \\
\hline Male & 41.5 & 58.5 & 57.5 & 42.5 & 64.6 & 35.4 & 60.8 & 39.2 & 65.2 & 34.8 \\
\hline Female & 69.6 & 30.4 & 88.7 & 11.3 & 88.2 & 11.8 & 91.1 & 8.9 & 94.5 & 5.5 \\
\hline
\end{tabular}

UUT: Upper Urinary Tract, LUT: Lower Urinary Tract

Table 6 Evolution of the number and the size of lithiasis between 1965 and 2014 at the level of Urology service of the University Hospital center of Oran

\begin{tabular}{|c|c|c|c|c|c|c|c|c|c|c|c|}
\hline \multirow{3}{*}{$\begin{array}{l}\text { Variables } \\
\text { Stone number }\end{array}$} & \multicolumn{10}{|l|}{ Periods } & \multirow[t]{3}{*}{$\mathbf{P}$} \\
\hline & \multicolumn{2}{|c|}{ 1965-1974 } & \multicolumn{2}{|c|}{ 1975-1984 } & \multicolumn{2}{|c|}{ 1985-1994 } & \multicolumn{2}{|c|}{ 1995-2004 } & \multicolumn{2}{|c|}{$2005-2014$} & \\
\hline & Number & $\%$ & Number & $\%$ & Number & $\%$ & Number & $\%$ & Number & $\%$ & \\
\hline 01 stone & 169 & 89.4 & 568 & 79.8 & 696 & 72.7 & 675 & 64.9 & 734 & 67.3 & $<0.001$ \\
\hline 02 and more & 20 & 10.6 & 144 & 20.2 & 261 & 27.3 & 365 & 35.1 & 357 & 32.7 & \\
\hline \multirow[t]{2}{*}{ Size } & \multicolumn{2}{|l|}{$A \vee g \pm S D$} & \multicolumn{2}{|l|}{$A v g \pm S D$} & \multicolumn{2}{|l|}{$A \vee g \pm S D$} & \multicolumn{2}{|l|}{$A v g \pm S D$} & \multicolumn{2}{|l|}{$A \vee g \pm S D$} & $<0.002$ \\
\hline & \multicolumn{2}{|l|}{$2.41 \pm 1.50$} & \multicolumn{2}{|l|}{$2.35 \pm 1.40$} & \multicolumn{2}{|l|}{$2.26 \pm 1.59$} & \multicolumn{2}{|l|}{$2.32 \pm 1.54$} & \multicolumn{2}{|l|}{$2.05 \pm 1.24$} & \\
\hline
\end{tabular}

Avg: average, SD: standard deviation 
that the actual number of operations done for urolithiasis in this region is higher.

Urolithiasis is a disease that affects both sexes in all age groups. However, various epidemiological studies suggest that lithogenic mechanisms change with sex and age [6, 7]. Thus, it affects mostly men, although the prevalence of urolithiasis in women seems to be increasing during these last years [6-8]. In our cohort, we observe a global ratio $\mathrm{M} / \mathrm{F}$ of 2.07. The analysis of the evolution of this ratio over time shows a significant decrease $(p<0.01)$ of the male predominance between 1965 and 2014 with an $\mathrm{M} / \mathrm{F}$ ratio which decreased from 3.09 to 1.82 . These results resemble those reported by several authors. The ratio M / F has passed for Lieske et al. from 3.1 to 1.3 in the region of Rochester between 1960 and 2000 [9] and from 1.7 to 1.3 between 1997 and 2002 for the Preminger group [10]. Similar observations have been found in Japan where the M/F ratio reduced from 2.8 in 1965 to 1.8 in 1995 [11]. In our study, during the last two decades, this ratio seems to stabilize (between 1.8 and 2) and stays in the average of the literature. In France, the M/F ratio is practically stable since about twenty years, at around 2.1 [1].

It was also observed that the average age tends to increase, changing from 28.8 years in the period 19651974 to 48.3 years between 2005 and 2014. A progressive change in the distribution of lithiasis to higher age groups was noted. Recent studies have shown that the average age of first episode of urolithiasis in a given population varies over time depending on changes in the socio-economic level, the medical or health means, and the lifestyle of the considered population [12, 13]. In France, the study of Daudon on the evolution of lithiasis according to the age was given for two periods: between 1978 and 1985 and between 2000 and 2004 [13]. This study noted in the second period a shift toward the higher age groups in the appearance of the first episode of calculus.

Today, the large majority of stones are formed in the kidneys and some of them can then descend into the ureter before being expelled by natural ways [1]. This was verified in our study because in the period 20052014 , more than three quarters of the stones $(75.8 \%)$ are located in the upper urinary tract. This frequency was 48.1\% between 1965 and 1974 with a dominance of vesical lithiasis.

As for the laterality of the stones and according to the data in the literature, often based on limited series of stones, there is only a very limited preponderance of either the right or left sides, depending on the studies. In a study of 1354 calculus collected in Algeria, Djelloul et al., [14] showed a dominance of left sided stones (56.4\% vs. $42.5 \%, p<0.001)$. However, the Study of Hesse et al., done in Germany and covering 10,000 stones, revealed no significant difference in the lateralization of stones [15]. In our series and before 2005, more than half of the upper urinary tract stones are located on the right side. This situation was reversed after this year, with a slight dominance on the left side. In both cases, no significant difference was recorded.

Another factor considered in our study is the size of stones. A significant tendency toward the decrease of the average size of the stones from 2.41 to $2.05 \mathrm{~cm}$ was noted $(p<0.002)$. This can be explained by modern urological techniques. Since a few years, ureteroscopy knows an important development significantly because it is a minimally invasive technique that does not alter the renal parenchyma and because that recent soft ureteroscopes provide natural access to the cavities kidneys and treat the stones in situ. All these techniques led to a faster treatment than previously of the stones found in the kidney, which significantly reduced the frequency of large stones [1]. On the other hand, these techniques may result in residual fragments in the urinary tract, which may be the core of new stones. In addition to the better health seeking habit of the population, due to early presentation, this may explain the increase in the frequency of multiple urolithiasis observed in our study where only $10.6 \%$ of lithiasis formed more than one stone between 1965 and 1974, whereas after 2005, this frequency has increased up to $32.7 \%$.

\section{Conclusion}

The comparison of epidemiological data over a period of 50 years shows that in Algeria, urolithiasis is in constant evolution as has been observed in other countries of the world. The characteristics of this disease are similar to those reported in the industrialized countries and testify to the gradual increase of the socio-economic level, of which the urolithiasis is often a reflection. In addition to the gradual decrease in the $\mathrm{M} / \mathrm{F}$ ratio and the increase in the average age of lithiasis, changes in anatomical localization have been observed with stones being more and more often located in the upper urinary tract, as in the industrialized countries.

This study concerns only the Urology service of the University Hospital Center of Oran (UHC). The data do not give information about the prevalence of urolithiasis in our region because of the limitations encountered. For a more precise situation in our region of Western Algeria, a collaboration between universities and hospitals in the region is necessary.

\section{Abbreviations}

Avg: Average; SD: Standard deviation; UUT: Upper urinary tract; LUT: Lower urinary tract. 


\section{Authors' contributions}

The epidemiological study of urinary lithiasis carried out at the hospital in Oran was based on the archives of the files of patients who underwent surgical interventions on the urinary tract to extract urinary lithiasis, the data of this study have been analyzed and interpreted by all authors.

\section{Funding}

No funding was provided for this study.

\section{Declarations}

\section{Ethics approval and consent to participate}

The data used in this article was accessed and published with the permission of The Epidemiology Service of the University Hospital of Oran (CHUO).

\section{Competing interests}

The author declares that he has no competing interests.

\section{Author details}

${ }^{1}$ STEVA « Environmental Science and Technology and Valorisation Laboratory», Départment of Biology, Faculty of Natural Sciences and Life, University Abdelhamid Ibn Badis, 27000 Mostaganem, Algeria. ${ }^{2}$ Department of Biostatistics, Faculty of Medicine, University of Oran, Oran, Algeria. ${ }^{3}$ Urology Service, University Hospital Center (UHC), Oran, Algeria.

Received: 1 February 2021 Accepted: 11 July 2021

Published online: 20 October 2021

\section{References}

1. Daudon M, Traxer O, Lechevallier E, Saussine C (2008) Épidémiologie des lithiases urinaires. Prog Urol 18(12):802-814

2. Castiglione V, Jouret F, Bruyere O, Dubois B, Thomas A, Waltregny D, Bekaert AC, Cavalier E, Gadisseur R (2015) Épidémiologie de la lithiase urinaire en Belgique sur base d'une classification morpho-constitutionnelle. Nephrol Ther 11(1):42-49

3. Oberlin DT, Flum AS, Bachrach L, Matulewicz RS, Flury SC (2015) Contemporary surgical trends in the management of upper tract calculi. J Urol 193(3):880-884
4. Doizi S, Raynal G, Traxer O (2015) Évolution du traitement chirurgical de la lithiase urinaire sur 30ans dans un centre hospitalo-universitaire. Progrèsenurologie 25(9):543-548

5. Lee MC, Bariol SV (2011) Evolution of stone management in Australia. BJU Int 108(Suppl. 2):S29-S33

6. Knoll T, Schubert AB, Fahlenkamp D, Leusmann DB, Wendt-Nordahl G, Schubert $G$ (2011) Urolithiasis through the ages: data on more than 200,000 urinary stone analyses. J Urol 185(4):1304-1311

7. Daudon M, Dore JC, Jungers P, Lacour B (2004) Changes in stone composition according to age and gender of patients: a multivariate epidemiological approach. Urol Res 32(3):241-247

8. Curhan GC (2007) Epidemiology of stone disease. Urol Clin North Am 34(3):287-293

9. Lieske JC, Peña de la Vega JS, Slezak JM, Bergstralh EJ, Leibson CL, Ho KL, Gettman M (2006) Renal stone epidemiology in Rochester, Minnesota: an update. Kidney Int 69(4):760-764

10. Scales CD, Curtis LH, Norris RD, Springhart WP, Sur RL, Schulman KA, Preminger GM (2007) Changing gender prevalence of stone disease. J Urol 177(3):979-982

11. Yoshida O, Terai A, Ohkawa T, Okada Y (1999) National trend of the incidence of urolithiasis in Japan from 1965 to 1995. Kidney Int 56(5):1899-1904

12. Robertson WG (2001) The changing pattern of urolithiasis in the UK and its causes. In: Kok DJ, Romijn HC, Verhagen PCMS, Verkoelen CF (eds) Eurolithiasis. Maastricht, Shaker

13. Daudon M (2005) Épidémiologie actuelle de la lithiase rénale en France. Ann Urol 39(6):209-231

14. Djelloul Z, Djelloul A, Bedjaoui A, Kaid-Omar Z, Attar A, Daudon M, Addou A (2006) Lithiase urinaire dans l'Ouest Algérien : étude de la composition de 1354 calculs urinaires en relation avec leur localisation anatomique, l'âge et le sexe des patients. Progrèsen Urologie 16(3):328-335

15. Hesse A, Schneider HJ, Schroder S, Wegner R (1976) Results of analyses of 10,000 urinary calculi using electronic data processing methods. Zeitschriftfür Urologie und Nephrologie 69:1-9

\section{Publisher's Note}

Springer Nature remains neutral with regard to jurisdictional claims in publishedmaps and institutional affiliations.

\section{Submit your manuscript to a SpringerOpen ${ }^{\circ}$ journal and benefit from:}

- Convenient online submission

- Rigorous peer review

- Open access: articles freely available online

- High visibility within the field

- Retaining the copyright to your article

Submit your next manuscript at $\boldsymbol{\nabla}$ springeropen.com 